Academic Platform Journal of Engineering and Science

\title{
Toz Metalurjisi Yöntemiyle Mg-Sn Alaşımı Üretimi ve Karakterizasyonu
}

\author{
*1,2 Azim Gökçe \\ ${ }^{1}$ Metalurji ve Malzeme Müh. Bölümü, Teknoloji Fakültesi, Sakarya Uygulamalı Bilimler Üniversitesi, Sakarya, Türkiye \\ ${ }^{2}$ Materials Innovation Guild, Mechanical Engineering Department, University of Louisville, Louisville, Kentucky, USA \\ azimg@ subu.edu.tr,
}

Araștırma Makalesi

Geliș Tarihi: 24.06.2019

Kabul Tarihi: 24.11.2019

$\ddot{O} z$

Magnezyum alaşımları özellikle düşük yoğunlukları ve yüksek spesifik dayanımları nedeniyle günden güne daha geniş alanlarda kullanım imkanı bulmaktadır. Bu alaşımların endüstriyel uygulamalarda daha yüksek oranda kullanımının önündeki en büyük engel hegzagonal sıkı paket olan kristal kafes yapısından dolayı geleneksel yöntemlerle plastik deformasyon işlemlerinin zor olmasıdır. Bu zorlukların üstesinden gelmek için kullanılabilecek yöntemlerden biri toz metalurjisi (TM) ile üretimdir. Bu çalışmada ticari olmayan bir tozmetal magnezyum alaşımı toz metalurjisi yöntemiyle geliştirilmiş ve geliştirilen alaşımın mikroyapısal özellikleri incelenmiştir. Çalışma sonucunda magnezyuma yapılan Sn ilavesi ile tane boyutunda ve dolayısıyla sertlik değerlerinde yükselme tespit edilmiştir. Ayrıca magnezyuma yapılan $\mathrm{Sn}$ ilavesi ile $\mathrm{Mg}_{2} \mathrm{Sn}$ fazının oluştuğu görülmüştür. Kalay ilavesi ile daha düşük sıcaklıklarda yapılan sinterleme işlemlerinde yüksek yoğunluk değerlerine ulaşılabildiği tespit edilmiştir.

Anahtar Kelimeler: Magnezyum, Toz metalurjisi, Sinterleme

\section{Development and Characterization of Mg-Sn Powder Metallurgy Alloy}

\author{
*1,2Azim Gökçe \\ ${ }^{1}$ Metallurgical and Materials Engineering Department, Sakarya University of Applied Sciences, Sakarya, Turkey \\ ${ }^{2}$ Materials Innovation Guild, Mechanical Engineering Dept., Uniersity of Louisville, Louisville, Kentucky, USA \\ azimg@subu.edu.tr
}

\begin{abstract}
Magnesium alloys have received increasing attention due to their low density and high specific strength. Magnesium has hexagonal closed packet crystal structure at all temperatures and therefore it is very difficult to give shape to the magnesium by using conventional plastic deformation methods. One of the methods that can be used to overcome this poor deformability problem is using powder metallurgy. In this study, a non-commercial powder metal magnesium alloy was developed and the properties of the alloy were investigated. It has been observed that the addition of Sn to magnesium decreased the grain size and hence increased the hardness values. Also formation of the $\mathrm{Mg}_{2} \mathrm{Sn}$ phase contributed to the achievement of the higher hardness values. It was determined that the addition of tin makes it possible to reach the higher density values even by sintering conducted at the lower temperatures.
\end{abstract}

Keywords: Magnesium, Powder metallurgy, Sintering

\section{GİRİs}

Magnezyum, yapısal uygulamalar için kullanılabilecek metalik malzemeler arasında en düşük yoğunluğa $(1,738$ $\mathrm{g} / \mathrm{cm}^{3}$ ) sahip olan malzemedir. Magnezyumun yoğunluğu, en çok kullanılan metalik malzeme olan çeliğin yaklaşık $1 / 4$ 'ü ve en çok kullanılan hafif alaşım olan alüminyumun $2 / 3$ ' $\ddot{u}$ kadardır. Ayrıca iyi dökülebilirlik, yüksek basınçlı döküm işlemleri için uygun özellikte olma, kontrollü atmosferde iyi kaynaklanabilirlik, geri dönüșebilirlik gibi özelliklerinden dolayı kullanım alanları her geçen gün artmaktadır [1]. Magnezyum kullanımı 1950'den günümüze 10 kat kadar artarak yıllık olarak yaklaşık 1 milyon tona ulaşmıştır. Ancak üretilen magnezyumun büyük bir kısmı ( \% 33) alüminyum için alaşım elementi olarak kullanılmaktadır [2]. Üretimi için gerekli enerjinin alüminyuma göre yaklaşık \% 50 daha fazla olması nedeniyle üretim maliyeti nispeten yüksektir [3]. Ayrıca oksijene karşı yüksek afinitesi nedeniyle geri 
dönüşümü için gerekli basamak sayısı alüminyum için gerekli basamak sayısından fazladır dolayısıyla, geri dönüşüm maliyeti daha yüksektir [4]. Ayrıca magnezyumun kıvılcımla tutuşabilir olması ve oksijenle tepkimeye girmesi nedeniyle döküm işlemlerinin kontrollü atmosfer altında yapılması gereklidir [5], [6]. Ancak magnezyumun endüstriyel anlamda geniş kullanım alanı bulmasının önündeki en büyük iki engel olarak düşük dayanım özellikleri ve düşük şekillendirilebilirliği sayılabilir. Düşük dayanım sorununu ortadan kaldırmak için çeşitli alaşım elementleri eklenerek nispeten yüksek dayanımlı alaşımlar üretilmekteyse de yapısal uygulamalar için gerekli dayanıma henüz ulaşılamamıştır. Karmaşık şekilli parça üretimi içinse yüksek basınçlı döküm kullanılmaktadır ve bu yöntemle gravite döküme göre daha düşük tane boyutlarına ulaşllabilmektedir [7], [8].

Karmaşık şekilli parça üretiminde kullanılabilecek bir diğer yöntem toz metalurjisi (TM) yöntemidir. $\mathrm{Bu}$ yöntemin avantajları olarak düşük enerji ile hammaddenin nerdeyse $\%$ 99'unun ürüne dönüşmesi, her tür malzemeye uygun olması, alaşımlama imkanlarının sınırsız olması, döküm için uygun olmayan W gibi yüksek ergime noktasına sahip malzemelerle üretime uygun olması, kontrol edilebilir gözenekli üretime imkan sağlaması, üretim sonrası işlemlere gerek duyulmaması gösterilebilir[9]. Yöntem otomasyona uygun olması ve yüksek boyut hassasiyeti nedeniyle de diğer imal usullerine göre avantajlıdır[10].

Magnezyum alaşımlarının kristal kafes yapısı nedeniyle haddeleme ve ekstrüzyon gibi yöntemlerle şekillendirilebilirliğinin kısıtlı olması bu alaşımların alternatif yöntemlerle şekillendirilmesi konusunda çalışmalar yapılmasını gerekli hale getirmiştir [11], [12]. Toz metalurjisi yöntemi, özellikle günümüzde öne çıkan hızlı prototipleme ve 3 boyutlu yazıcilarla sinırsiz dizayn imkanları sunulması nedeniyle diğer yöntemlere göre öne çıkmaktadır. Bu çalışmada bir ikili Mg alaşımın ( $\mathrm{Mg}-\mathrm{Sn})$ toz metalurjisi yöntemiyle üretilebilirliği ve üretim parametrelerinin ürün özellikleri üzerindeki etkisi incelenmiştir. $\mathrm{Bu}$ amaçla elementel tozlar belirtilen kompozisyonlarda alaşımlandırılmış ve sonuçlar metalürjik karakterizasyon teknikleriyle analiz edilmiştir.

\section{MALZEME ve METOD}

\subsection{Malzeme}

Alaşım üretimi için elementel tozlar tercih edilmiştir. Hammadde hakkında gerekli bilgiler Tablo 1'de verilmiştir.

Tablo 1. Hammadde olarak kullanılan tozların özellikleri.

\begin{tabular}{|l|c|c|c|c|}
\hline \multirow{2}{*}{ Toz } & Safiyet (\%) & \multicolumn{3}{|c|}{ Tane boyut değeri $(\mu \mathrm{m})$} \\
\cline { 3 - 5 } & & $\mathrm{D}_{10}$ & $\mathrm{D}_{50}$ & $\mathrm{D}_{90}$ \\
\hline $\mathrm{Mg}$ & 99,99 & 24,12 & 52,23 & 91,47 \\
\hline $\mathrm{Sn}$ & 99,80 & 8,60 & 23,81 & 42,58 \\
\hline
\end{tabular}

Magnezyum tozları Magnezyum Metal Tozları Endüstri A.Ş.'den kalay tozları ise Alfa Aesar'dan temin edilmiş̧ir. Toz boyut dağılımı ölçümleri Microtrac S3500 lazer partikül boyut analizi cihazı kullanılarak, toz morfolojisi incelemeleri JEOL JSM 6060LV taramalı elektron mikroskobu (SEM) kullanılarak yapılmıştır. Tozlar istenilen bileşimde olacak şekilde 0,0001 hassasiyetli terazide tartılarak yüksek yoğunluklu polietilen kavanoza yerleştirilmiştir. Üretilen alaşımda ağırlıkça $\% \quad 6 \quad$ kalay, \% 94 magnezyum bulunmaktadır. Polietilen kavanozlar hacimce $1 / 3$ toz, 1/3 $\mathrm{Zr}_{2} \mathrm{O}_{3}$ bilye ( $7 \mathrm{~mm}$ çapında), 1/3 boşluk olacak şekilde doldurularak kavanoz Turbula T2F karıştırıcıya yerleştirilmiş ve 30 dakika boyunca tozların homojen bir karışım haline gelmesi sağlanmıştır. Karışım işlemi sonrasında seramik bilyeler karışımdan elek kullanılarak ayrılmıştır.

\subsection{Toz Şekillendirme}

Toz şekillendirme işlemleri için tek eksenli yükler altında çalışan bir kalıp kullanılmıştır. Kalıp boşluğu $10 \mathrm{~mm}$. çapındadır ve üretilen numunelerin yüksekliği $\sim 5 \mathrm{~mm}$. olacak şekilde kalıba toz yüklemesi yapılmıştır. Kalıp boşluğu her işlemden önce kalıp aşınmasını engellemek ve kalıbın sıkıştırma sonrası kolay çıkmasını sağlamak amacıyla Zn stereat-alkol karışımı sprey ile kaplanmış ve sonrasında alkol uçurulmuş ve kalıp yüzeyinde yağlayıcı olarak Zn stearatın kalması sağlanmıştır.

Alaşımın şekillendirilebilme davranışının incelenmesi amacıyla 100-600 MPa arasında 6 ayrı sıkıştırma basıncı kullanılmıştır. Toz şekillendirme işlemleri 25 metrik ton kapasiteli MSE marka ve LP-M2S20 model manuel kontrollü preste yapılmıştır.

\subsection{Sinterleme}

Sinterleme işlemleri Honeywell DC 2500 kontrolör ile sıcaklık kontrolü yapılan 316L paslanmaz çelik tüp firında yüksek safiyette azot atmosferi altında yapılmıştır. Numuneler ile paslanmaz çelik tüp arasında oluşabilecek muhtemel difüzyonu engellemek amaciyla numuneler alümina altlıklar üzerine yerleştirilmiştir. Sinterleme başlamadan önce firını oksijenden arındırabilmek için firın 3 defa vakumlanmış ve vakumlanan firına azot verilmiştir. Ayrıca azot içindeki olası oksijen kontaminasyonunu engellemek için gaz tüpü ile firın arasına silika jel ile doldurulmuş gaz yıkama şişesi yerleştirilmiştir. Kullanılan temsili sıcaklık-zaman grafiği Şekil 1'de verilmiştir. Sinterlemenin son aşamasında soğuma eğrisi her ne kadar 15 ${ }^{\circ} \mathrm{C} / \mathrm{dk}$ olarak verilmişse de, kullanılan firının soğutma sistemi olmadığı için soğuma hızı verilen değerden daha düşüktür. Konuyla ilgili detaylı bilgi daha önceki çalışmalarımızda verilmiştir [13], [14]. Sinterleme çalışmalarında 500,550 ve $600 \mathrm{C}$ olmak üzere 3 ayrı sinter sıcaklığı kullanılmıştır. 


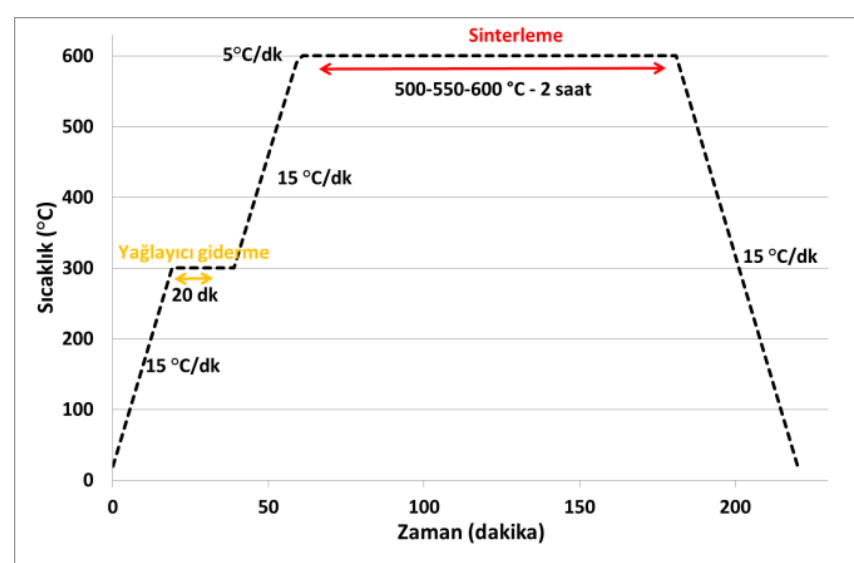

Şekil 1. Sinterleme çalışmalarda kullanılan zaman-sıcaklık grafiği.

\subsection{Karakterizasyon}

Sinterleme öncesi kompaktlardaki gözenekler açık gözenek şeklindedir ve siviyla temas etmeleri halinde toz partiküllerinin oksijenle reaksiyona girmesi durumunda yüzey oksidi kalınlığı artacaktır. Bu durumdan kaçınmak için şekillendirme sonrası kompaktların ham yoğunluğu, arşimet metodu yerine hacimlerinin kütlelerine bölünmesi ile tespit esilmiştir. Hacim tespiti sırasında 0,001 mm hassasiyetli kumpas ve kütle tespitinde $0,0001 \mathrm{~g}$ hassasiyetli terazi kullanılmıştır. Alaşımların teorik yoğunluğunun hesaplanmasında Denklem 1 kullanılmıştır [15]. Denklemde $\mathrm{m}$, alaşıma eklenen elementlerin kütlesini, $\mathrm{d}$ ise yoğunluklarını göstermektedir.

$T Y=\frac{m_{a}+m_{b}}{\frac{m_{a}}{d_{a}}+\frac{m_{b}}{d_{b}}}$

Üretilen alaşımların yoğunlukları teorik yoğunluk (TY) değerlerine bölünerek \% TY değerleri hesaplanmıştır. Sinterleme sonrası yoğunluklar Arşimed metosu kullanılarak tespit edilmiştir.

Mikroyapısal analiz için standart metallografi işlemleri kullanılmış olup son parlatma işlemi kolloidal silika ile yapılmıştır. Dağlayıcı olarak \% 3 Nital kullanılmıştır. Optik mikroyapı görüntüleri Nikon Eclipse L50 metal mikroskobu ile kaydedilmiş SEM analizinde toz morfolojisi analizi için kullanılan SEM cihazı kullanılmıştır. XRD analizi Rigaku D/Max 2200 X-Işınımı Kırınım cihazı ile yapılmıştır.

Sertlik değerleri ilgili standarda göre $31,25 \mathrm{~kg}$ yükün $30 \mathrm{sn}$ bir süreyle uygulanması sonucu Brinell sertlik skalası cinsinden tespit edilmiştir. Her bir parametre için 5 ölçüm yapılmış ver ortalama değer ilgili parametre için sertlik değeri olarak kabul edilmiştir.

\section{SONUÇLAR ve TARTIŞMA}

Toz metalurjisi ile üretim süreçlerinde toz morfolojisinin nihai ürün üzerinde önemli etkileri olduğu bilinmektedir [16]. Deneysel çalışmalarda kullanılan magnezyum tozları magnezyum kütleden kazıyarak üretimin gereği olarak yar1pulsu morfolojiye sahiptir (Şekil 2-a). Kalay tozları ise atomizasyonla üretilmiş olmalarından dolayı yarı küresel veya yuvarlatılmış morfolojidedir (Şekil 2-b). Tablo 1'de de belirtildiği üzere kalay tozlarının tane boyutu magnezyuma göre çok düşüktür. Şekil 2'de verilen görüntüler aynı büyütme değerinde(500X) alınmasına rağmen tozlar arasındaki boyut farkı rahatlıkla fark edilebilir niteliktedir. Toz boyutu düştükçe, tozlar arasındaki sürtünme kuvvetleri artacağı için, toz akış özelliğinin düşmesi beklenmektedir [10]. Ancak çalışmalar sırasında her iki toz grubunun da gerek alaşım haline getirilmek üzere karıştırılmadan önce gerekse istenilen bileşimde karıştırıldıktan sonra iyi akış özelliği sergilediği görülmüştür. Toz metalurjisi işlemlerinde en büyük gider kalemlerinden birini kalıp maliyetleri oluşturmaktadır [17]. Nispeten daha yüksek sertliğe sahip önalaşımlı tozlar yerine daha düşük sertlikteki elementel metal tozlarının kullanımıyla kalıp aşınmasının ve dolayısıyla kalıp ömrünün daha uzun olması beklenmektedir. Önalaşımlı toz yerine elementel toz kullanmanın en büyük handikapı ise karıştırma işlemlerinin iyi yapılmadığı durumlarda homojen olmayan mikroyapı ile karşılaşılmasıdır[18]. Çalışmada kullanılan karıştırıcı için daha önce yapılmış optimizasyon çalışmasında belirlenmiş olan süreden daha uzun süreli bir karıştırma işlemi yapılması ile toz partiküllerinin birbiri içinde homojen dağılması sağlanmıştır.

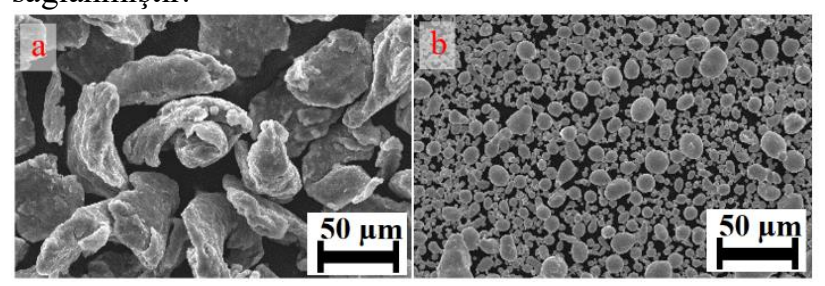

Şekil 2. Deneysel çalışmalarda kullanılan a)Mg b)Sn tozları

Tozların şekillendirilebilirlikleri, çeşitli şekillendirme basınçları altında şekillendirererek ölçülmüştür (Şekil 3). Magnezyuma kalay ilavesinin düşük (100 MPa) ve yüksek (> $400 \mathrm{MPa}$ ) şekillendirme basınçlarında etkisi olmadığı, orta dereceli basınçlarda ise az miktarda ( $<\% 2$ TY) etkili olduğu görülmüştür. Bu durum tozlar arasındaki tane boyut farklılığına bağlanmaktadır. İnce taneli kalay partiküllerinin nispeten kaba taneli magnezyum partikülleri arasına girerek paketlenme yoğunluğunu artırması nedeniyle düşük basınçlarda daha yüksek yoğunluk elde edilirken özellikle yüksek basınçlarda oluşan plastik deformasyon nedeniyle toz morfolojisinin önemini kaybettiği görülmektedir. Kalay ilavesi ile birlikte düşük basınçlarda bile yüksek \% TY elde edilmesinin bir diğer sebebi kalayın sertlik değerlerinin daha düşük olması nedeniyle kalay partiküllerinin daha düşük basınç altında deforme olmasıdır. Ancak her iki malzemenin de düşük sertliğe sahip malzemeler olması nedeniyle partiküller nispeten düşük soğuk şekillendirme basınçlarında bile yüksek \% TY değerlerine ulaşmışlardır. Elde edilen ham yoğunluklar önalaşımlı AZ31 alaşımı kullanılarak yapılan bir çalışmada [19] elde edilenlerden daha yüksektir ve bu sonuç elementel tozların önalaşımlı tozlardan daha düşük sertlikte olmasına bağlanmıştır. 500 ve $600 \mathrm{MPa}$ basınç 
altında yapılan şekillendirme ile kompakt gözenekliliğinde çok düşük miktarda düşme görülse bile gerek yüksek basınçlarda yapılan şekillendirmede kalıp aşınmasının artması ve kalıp ömrünün düşmesi [20], [21] gerekçesiyle $400 \mathrm{MPa}$ üzerindeki şekillendirme basınçlarının endüstriyel üretim aşamasında kullanılabilmesi öngörülmemektedir. Ham yoğunluk artışının $400 \mathrm{MPa}$ üzerinde çok düşük olması belirtilen bu basincın, elementel tozlar kullanılarak üretilen magnezyum alaşımlarının TM işlemlerinde kullanılabileceği sonucunu ortaya çıkarmıştır. Presleme sonucunda tüm kompaktların elle tutulabilir ve bir sonraki aşama olan sinterleme aşamasında kullanılacak basamaklar için gerekli ham dayanım değerlerine sahip olduğu tespit edilmiştir.

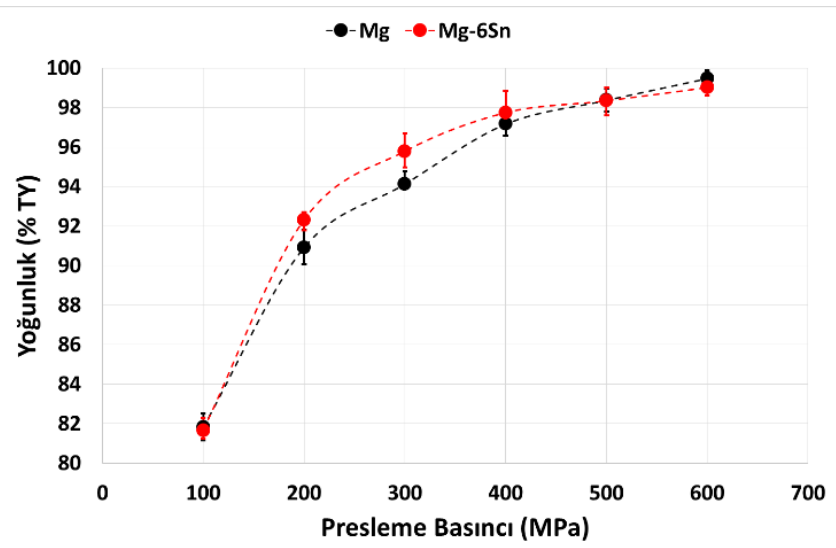

Şekil 3. Presleme basıncının ham yoğunluk üzerine etkisi.

Sinterleme sıcaklığının magnezyum kompaktların yoğunluğu üzerindeki etkisi Şekil 4'de verilmiştir. Magnezyumun ergime sicaklığ $650{ }^{\circ} \mathrm{C}$ 'dir. Sinterleme Magnezyum tozlarına herhangi bir alaşım elementi veya sinterleme yardımcısı eklenmediği için yapılacak sinterleme türü katı faz sinterleme olarak değerlendirilmektedir[22]. Katı faz sinterlemede partiküllerin temas noktalarında oluşacak boyunlar vasitasıyla atom difüzyonu gerçekleşmekte ve boyunların genişlemesiyle gözenekler kapanarak rijit parçalar oluşması sağlanmaktadır. Dolayısıyla partiküller arası temas noktalarının artması, difüzyon için gerekli olan temas alanlarının artması anlamına gelmektedir. Bu yüzden yüksek şekillendirme basınçlarının kullanılması ile patiküller daha fazla deformasyona uğramaktadır ve partiküller arasında difüzyon imkanı artmaktadır. Daha önce yapılan bir çalışmada [23] $400 \mathrm{MPa}$ basınçla şekillendirilen alüminyum, bakır ve magnezyum tozlarının şekillendirme sonrası kırılmış yüzeyi incelendiğinde başlangıç morfolojilerinden tamamen farklı şekilde birbirlerinin içine geçerek difüzyon yüzeyleri oluşturdukları görülmüştür. Magnezyum tozlarının belirtilen çalışmada kullanılanlardan daha yumuşak karakterde olması sebebiyle çalışmada kullanılan tozların tamamen deforme olarak kendi aralarında geniş temas yüzeyi oluşturdukları söylenebilir. Katı faz sinterleme dikkate alınması gereken bir diğer etken sinterleme sicaklığıdır. Fick kanununa göre sıcaklık arttıkça difüze eden atom sayısı artacaktır[24]. Dolayısıyla yükssek basınçla şekillendirilen ve dolayısıyla yüksek deformasyona uğramış parçaların yüksek sıcaklıkta sinterlenmesi ile parçadaki gözenekliliğin düşmesi beklenmektedir ve sonuçlar (Şekil 4) bu beklentiyle uyumludur.

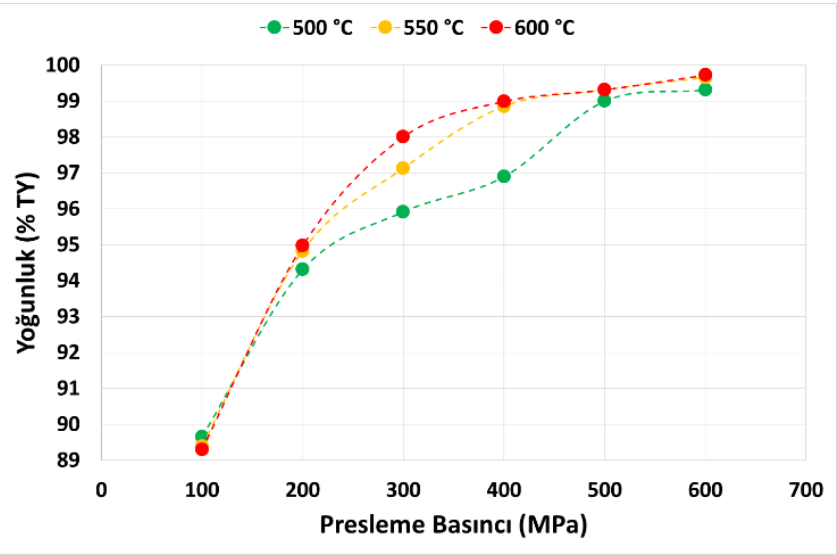

Şekil 4. Sinterleme sıcaklığının magnezyum kompaktların yoğunluk değerlerine etkisi.

Sıcaklıktaki artış kalay ile alaşımlanmış magnezyum için saf magnezyuma yaptığının tersine yoğunluk değerlerinde düşmeye neden olmuştur (Şekil 5). Kalayın ergime sıcaklığı $231{ }^{\circ} \mathrm{C}$ 'dir. Dolayısıyla elementel kalay tozları kullanılarak bu sıcaklık üzerinde yapılacak tüm sinterleme işlemleri sıvı faz sinterlemedir. Ayrıca kalayın magnezyum içine difüze etmesi ile birlikte $\mathrm{Mg}$-Sn ikili diyagramı incelendiğinde kalayca ve magnezyumca zengin 2 ötektik faz bulunmaktadır. Bunlardan kalayca zengin olanın (\% 97,87 Sn) ergime sıcaklığ $203{ }^{\circ} \mathrm{C}$, magnezyumca zengin olanın (\% $63,9 \mathrm{Mg}$ ) ergime sicaklığı ise $561{ }^{\circ} \mathrm{C}$ 'dir. Dolayısıyla sinterleme sırasında birden fazla sayıda geçici sıvı faz oluşmaktadır. Genellikle sıvı faz sinterlemede, oluşan sıvı fazın kapiler basınç ile kompakt içindeki gözenekleri doldurması sebebiyle daha düşük gözeneklilik görülmektedir[25], [26]. Deneysel çalışmalarda kullanılan sinterleme sicaklıklarından iki tanesi sadece bakırın ve bakırca zengin ötektik fazın ergime sıcaklığının üzerindeyken bir tanesi $\left(600{ }^{\circ} \mathrm{C}\right)$ ikili denge diyagramında görülen diğer sıvı fazların da oluşunu sağlayacak kadar yüksektir. Her ne kadar sıvı faz sinterlemede yoğunluğun daha yüksek olması beklense de sıvı faz miktarının belli miktarın üzerinde olması kompaktların şeklini koruyamamasına dolayısıyla boyut hassasiyetinin kaybolmasına yol açmaktadır[13]. Sıvı fazın belli bir miktarın altında olması durumundaysa özellikle alaşımların sinterlenmesinde yüksek miktarda gözeneklilik görülmektedir. Sinterleme sırasında kompakt boyutlarının artarak gözeneklilik oluşmasının başka bir sebebi alaşımı oluşturan elementlerin birbiri içindeki çözünürlükleri arasında yüksek fark olmasıdır[27]. Özellikle yüksek miktarda sıvı fazın oluşması kompaktların gözeneklilik değerlerinde artışa sebep olmuştur. Bununla birlikte sıvı fazın düşük olması durumunda düşük sıkıştırma basınçlarında bile düşük gözeneklilik değerlerine 
ulaşılmıştır. Yoğunluk değerleri daha önce yapılmış bir çalışma ile uyumludur [28].

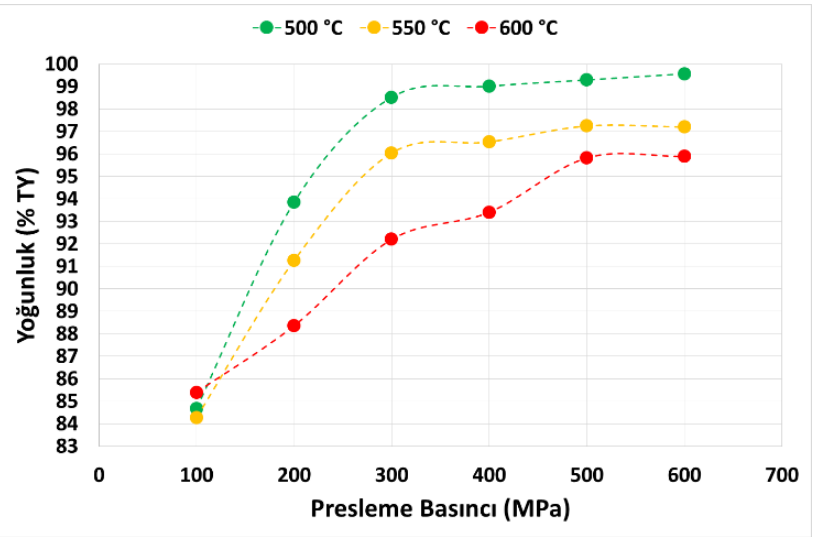

Şekil 5. Sinterleme sıcaklığının Mg-6Sn alaşımı kompaktların yoğunluğu üzerine etkisi.

Ortalamayı temsil ettiğinden dolayı ortalama presleme basıncında (400 MPa) preslenmiș ve $550{ }^{\circ} \mathrm{C}$ 'de sinterlenmiş magnezyum kompaktın XRD analizi yapılmıştır (Şekil 6). Analizde $\alpha$-Magnezyum ile birlikte $\mathrm{MgO}$ pikleri tespit edilmiştir. Magnezyumun oksijene olan yüksek afinitesinden dolayı partikül yüzeylerinde oluşan oksit tabakası sinterleme sonrasinda XRD analizinde $\mathrm{MgO}$ tespit edilmesine sebep olmuştur. Magnezyum partikülleri yüzeyindeki oksit tabakası çok incedir (5-6 nm. [29]) ancak partikül boyutunun küçük olması ve morfolojisinin pulsu olması sebebiyle oksijen miktarı önemli değerlere ulaşmaktadır. Magnezyumun genleşme katsayısının oksidinden daha fazla olması nedeniyle sinterlemenin kontrollü atmosferde yapılması halinde genleșen magnezyum, magnezyum oksit tabakasını çatlatarak partiküller arasında difüzyon köprüleri oluşumunu sağlayacaktır. Özellikle düzensiz şekilli partiküllerde bu tip genleşme sonucu oluşacak yüzey oksidi çatlaklarının daha çok oluşacağı rapor edilmiştir [30]. Yüzey oksidini indirgemek için kullanılabilecek bir diğer yöntem, oksijene afinitesi magnezyumdan daha yüksek olan bir sinterleme yardımcisı ilave edilmesidir [31], ancak bu çalışmada oksit indirgeme yöntemleri kullanılmamıştır.

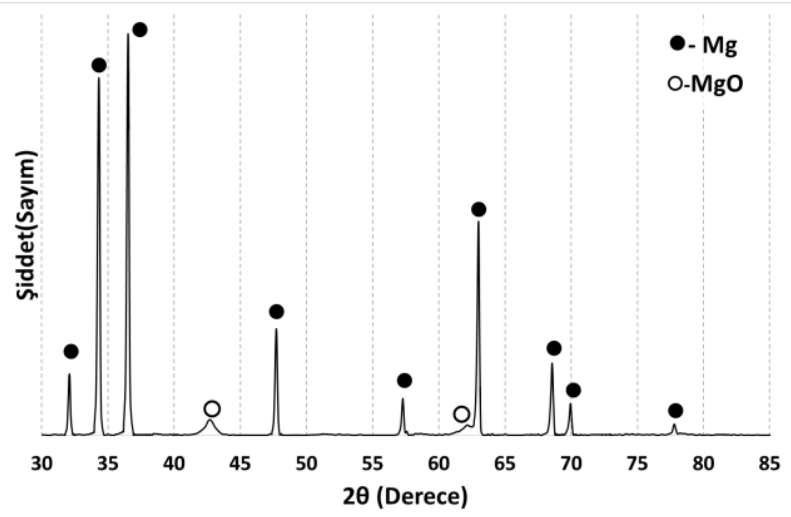

Şekil 6. $550{ }^{\circ} \mathrm{C}$ 'de sinterlenmiş magnezyum kompaktın XRD analizi.
$550{ }^{\circ} \mathrm{C}$ 'de sinterlenmiş Mg6Sn alaşımının XRD analizi (Şekil 7), kalay ilavesi ile birlikte $\mathrm{Mg}_{2} \mathrm{Sn}$ fazının oluştuğunu göstermektedir. XRD analizinde kalay pikinin bulunmaması kalayın tamamının veya büyük kısmının magnezyum içine difüzyonu sonucu $\mathrm{Mg}_{2} \mathrm{Sn}$ fazı oluşturmasına bağlanmış̧ır. XRD analizi $\mathrm{Mg}$-Sn ikili denge diyagramına bağlantılı olarak incelendiğinde alaşım matrisinin $\alpha-\mathrm{Mg}+\mathrm{Mg}_{2} \mathrm{Sn}$ 'den oluştuğu sonucuna varılmıştır. $\mathrm{Mg}$-Sn ikili denge diyagramına göre Mg6Sn tozları karışımının sinterlenmesi sırasında ilk olarak kalayın ergime sıcaklığına ulaşıldığında kalayın ergimesi beklenmektedir. Ancak bu sıcaklığın daha altında kalayca zengin bir ötektik fazın ergimesi söz konusudur. $\mathrm{Mg}_{2} \mathrm{Sn}+\mathrm{Sn}$ katı çözeltisi ağırlıkça \% 97,87 kalay bileşimine ulaştığında $203{ }^{\circ} \mathrm{C}$ 'de bir ötektik ergime gerçekleşmektedir. Ancak ergiyen ötektik fazın katı magnezyum partikülleri içine difüzyonu ile birlikte artan sıcaklıkla birlikte $\mathrm{Mg} 2 \mathrm{Sn}+\mathrm{Mg}$ katı çözeltisi $561{ }^{\circ} \mathrm{C}$ 'de ikinci bir ötektik reaksiyon meydana gelmektedir. Her iki ötektik fazda da bulunan $\mathrm{Mg}_{2} \mathrm{Sn}$ fazı XRD analizlerinde de tespit edilmiştir. Kalay ilavesinin $\mathrm{MgO}$ üzerinde herhangi bir etki yapması beklenmemektedir ve analizde de herhangi bir etkisi gözlemlenmemiştir.

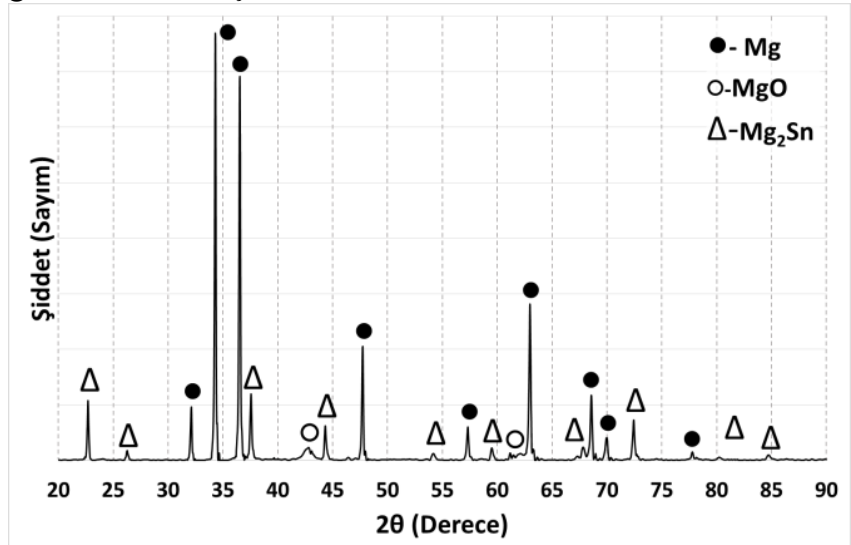

Şekil 7. $550{ }^{\circ} \mathrm{C}$ 'de sinterlenmiş Mg6Sn kompaktın XRD analizi.

Ortalamayı temsil eden $400 \mathrm{MPa}$ ile şekillendirilmiş kompaktın optik mikroyapı görüntüleri Şekil 8'de verilmiştir. Daha önce belirtildiği gibi bu kompaktlarda gerçekleşen sinterleme katı faz sinterlemedir ve mikroyapıda ikincil fazlar olmadığı için kontrast oluşturmak oldukça zordur. Ancak mikroyapı görüntüleri yoğunluk ölçümlerini doğrular niteliktedir ve gözeneklerin belli noktalarda toplanmadığ1 matris içinde homojen olarak dağıldığ görülmüştür. Sinterleme sirasında oluşan bileşenleri daha iyi analiz edebilmek için Geri Saçınım Elektron (BSI) modunda SEM görüntüsü alınmış ve Şekil 9'da verilmiştir. SEM görüntüsü katı faz sinterlemenin karaktersitik özelliklerini taşımaktadır [32]. Tane sınırları oldukça incedir ve takibi zordur. Ayrıca tane sinırlarını yanı sıra bazı partikül temas sınırları tespit edilmiştir ve belirtilen bölgeler tane sınırlarına göre daha belirgindir. 

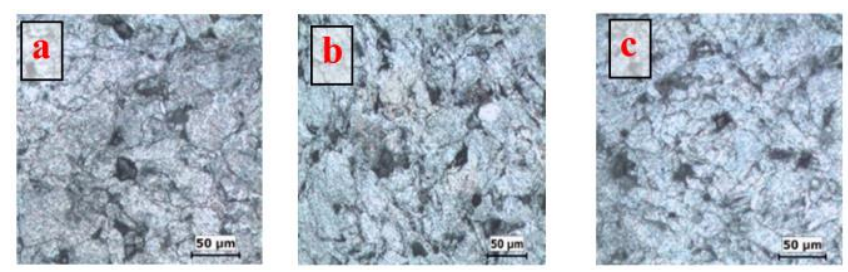

Şekil 8. Farklı sıcaklıklarda sinterlenmiş $\mathrm{Mg}$ kompaktın optik mikroyapı görüntüsü. a) $500{ }^{\circ} \mathrm{C}$ b) $550{ }^{\circ} \mathrm{C}$ c) $600{ }^{\circ} \mathrm{C}$

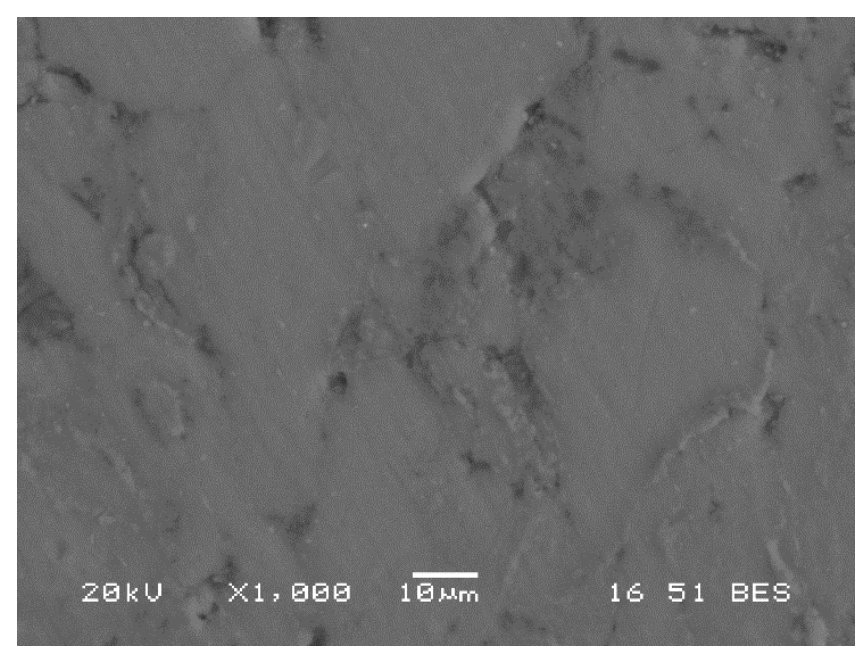

Şekil 9. $550{ }^{\circ} \mathrm{C}$ 'de sinterlenmiş $\mathrm{Mg}$ kompaktın SEM görüntüsü.

Saf magnezyuma kalay ilavesi ile birlikte mikroyapıda farklılıklar tespit edilmiştir. (Şekil 10). Kalay ilavesi ile birlikte tane sınırları daha belirgin bir hale gelmiştir. Sıvı faz sinterleme işleminde, oluşan sıvı fazın öncelikle partiküller arasındaki boşluğu doldurması ve sonrasında tanelere difüze etmesi dolayısıyla tane sinırı fazlarının, katı faz sinterlemeye göre çok daha fazla olması beklenen bir gelişmedir[33]. Mg6Sn alaşımında sıvı faza geçen ötektiğin magnezyumla birlikte $\mathrm{Mg}_{2} \mathrm{Sn}$ intermetaliğini içermesi nedeniyle tane sınırı fazı $\mathrm{Mg}_{2} \mathrm{Sn}$ 'ce zengindir dolayısıyla tane sinırlarındaki kalay miktarı matristekinden daha fazladır. Ayrıca partikül yüzeylerindeki oksijenden dolayı partikül sınırlarındaki oksijen miktarı matristen fazladır. Mikroyapı görüntüleri oluşan tanelerin eşeksenli yapıda olduğunu ortaya koymaktadır. Bununla birlikte sinterleme esnasında oluşan yüksek miktardaki sıvı fazın bazı bölgelerde yeterince matrise difüze etmemesi nedeniyle ötektik faza yakın bileşimde adacıkların olduğu açıkça görülmüştür.

$100 \mathrm{MPa}$ ile şekillendirilen kompaktların sertlik değerleri 2 sebeple ölçülememiştir. $\mathrm{Bu}$ sebeplerden birincisi numunelerin sertlik değerlerinin Brinell skalasılyla ölçülemeyecek kadar düşük olması diğeri ise yüksek gözeneklilik nedeniyle kompaktların sertlik ölçümü sırasında kırılmasıdır. Saf magnezyum kompaktların sertlik değeri artan sıcaklık ve presleme basıncına paralel olarak artmıştır (Şekil 11). Saf magnezyum numunelerin katı faz sinterleme ile artan sinter sicaklıklarında daha yüksek sertlik değerlerinin elde edilmesi artan sıcaklıkla birlikte artan atom difüzyonu miktarına ve dolayısıyla düşen gözenekliliğe (Şekil 4) bağlanmaktadır. $600 \mathrm{MPa}$ ile şekillenirilen kompaktın sertliği $200 \mathrm{MPa}$ ile şekillendirilen kompakttan \% 66 daha fazladır. Bununla birlikte $600 \mathrm{MPa}$ ile şekillendirilmiş ve $600{ }^{\circ} \mathrm{C}$ sıcaklıkta sinterlenmiş kompaktın sertliği aynı basınçla şekillendirilmiş ve $500{ }^{\circ} \mathrm{C}$ 'de sinterlenmiş numunenin sertliğinden $\% 23$ daha fazladır. Sertlik değerlerindeki değişim trendinin(Şekil 11) sinterleme sonrası yoğunluk değerlerinde meydana gelen değişim trendlerine (Şekil 4) çok benzer olması sebebiyle sertlik değerlerindeki değişimi etkileyen başlıca faktörün gözeneklilik olduğunu ortaya koymaktadır. Döküm yöntemiyle üretilmiş saf magnezyumun sertliği bir çalışmada 37 HBN olarak ölçülmüştür [34]. Bu sonuca göre $400 \mathrm{MPa}$ ve üzerindeki basınçlarda şekillendirilen ve $500^{\circ} \mathrm{C}$ üzeri sıcaklıklarda sinterlenen kompaktların sertlik değeri döküm yöntemiyle üretilene göre daha yüksektir.

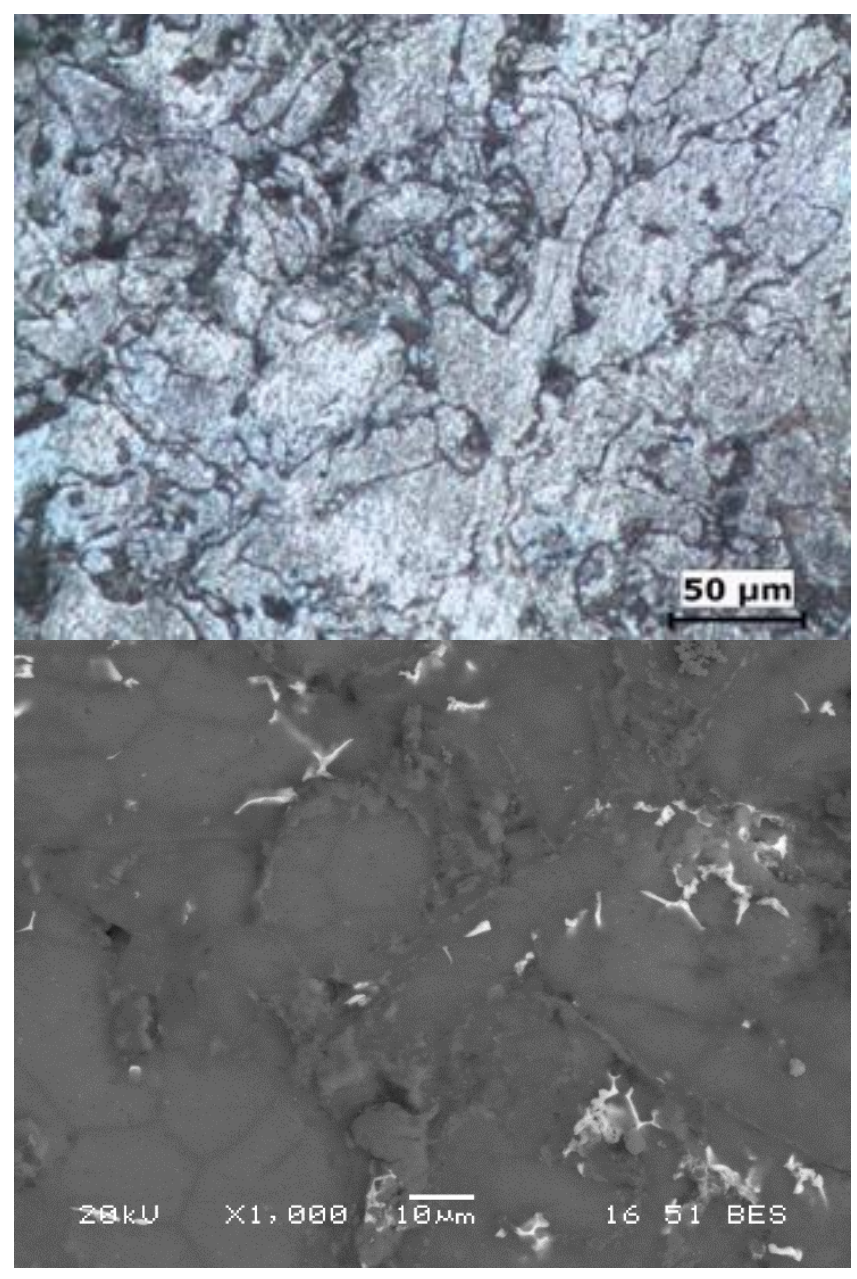

Şekil 10. $400 \mathrm{MPa}$ ile preslenmiş $550{ }^{\circ} \mathrm{C}$ 'de sinterlenmiş Mg6Sn alaşımına ait a) optik mikroskop ve b)SEM görüntüsü. 


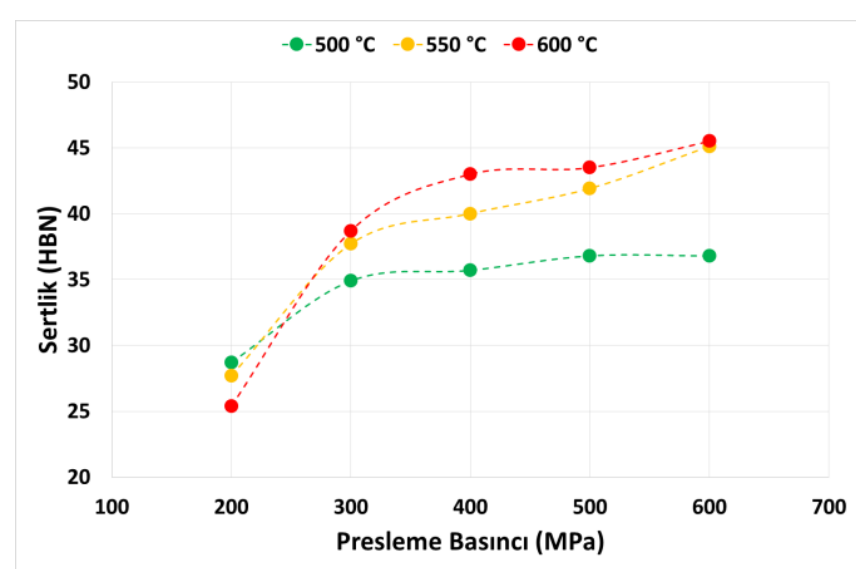

Şekil 11. Magnezyum TM kompaktların sertliğinin presleme basıncı ve sıcaklığa bağlı değişimi

Mg6Sn alaşımında da sertlik değişimi(Şekil 12) ile yoğunluk değişimi (Şekil 5) trendi birbirine benzerdir. Ancak sertlik değerleri saf $\mathrm{Mg}$ alaşımından daha yüksektir. Sertlik artışının başlıca sebebinin $\mathrm{Sn}$ ilavesi ile birlikte oluşan $\mathrm{Mg}_{2} \mathrm{Sn}$ intermetalik fazının matris içinde dağılarak dislokasyon hareketlerini engelleyici etki göstermesi olduğu düşünülmektedir [34]. Bununla birlikte yüksek basınçla sıkıştırılan numunelerde oluşan geniş atom difüzyonu duvarlarından dolayı atom difüzyonunun daha kolay olması beklenen bir durumdur [26]. Dolayısıyla yüksek basınçla sıkıştırılan numunelerde daha fazla intermetalik faz oluşumu meydana gelmiş ve bu numunelerde daha fazla sıvı faz oluşmuştur. Ancak fazla miktarda oluşan sıvı faz numunelerde genleşmeye yol açarak veya gözeneklerde numune dışına çıkarak daha düşük yoğunluk değerlerine ve daha düşük sertlik değerlerine sebep olmuştur. Ancak özellikle düşük sıcaklıkta $\left(500{ }^{\circ} \mathrm{C}\right)$ sinterlenen numunelerin sertlik değerleri döküm alaşımlarına [5] benzer seviyededir.

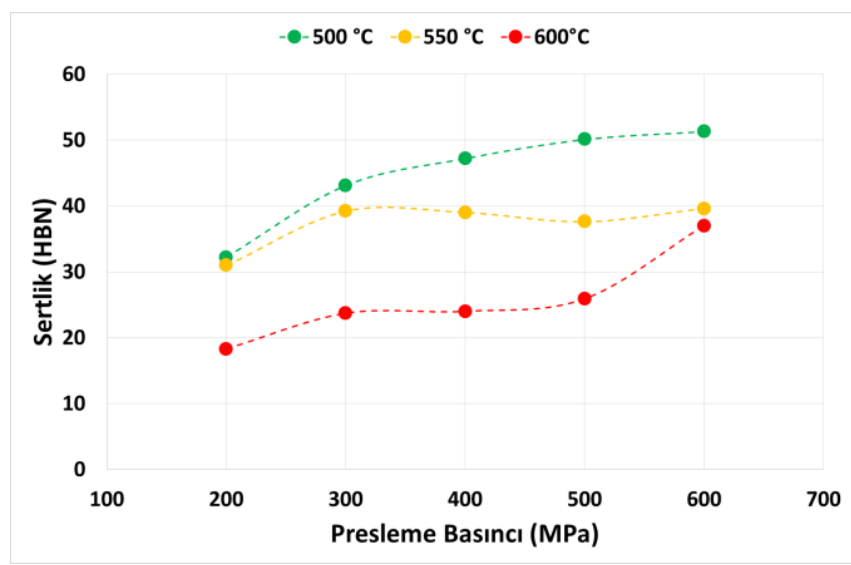

Şekil 12. Mg6Sn TM alaşımının sinterleme sıcaklığı ve presleme basıncına bağlı sertlik değişimi.

\section{DEĞERLENDİRME ve SONUÇ}

$\mathrm{Bu}$ çalışmada saf magnezyum ve seçilmiş bir magnezyum alaşımının (Mg- \% 6 Sn) elementel tozlar kullanılarak geleneksel TM süreçleriyle üretilebilirliği araştırılmıştır. Sonuçlar alaşımın üretilmesi için şekillendirme basıncı olarak $400 \mathrm{MPa}$ 'nın optimum değer olduğunu ve bu basınç üzerinde yoğunluk ve sertlikteki artışın önemsenmeyecek düzeyde olduğunu ortaya koymuştur. Ayrıca alaşım üretimi sirasında artan sicaklıkla birlikte artan sıvı faz miktarının özelliklerde olumsuz etki yaptığı tespit edilmiştir. Kalay ilavesi ile birlikte yüksek yoğunluğa çıkmak için gerekli olan sıcaklık düşmüştür. Üretilen alaşımların optimize edilmiş koşullarda sertlik değerleri döküm yöntemi ile üretilenlere benzerdir. Sonuç olarak magnezyumun yüzey oksidini indirgeyici element ( $\mathrm{Yb}, \mathrm{Ca}$ vs. ) kullanılması durumunda daha yüksek mekanik özellikler elde edilebileceği düşünülmektedir.

\section{TEŞEKKÜR}

$\mathrm{Bu}$ çalışma Sakarya Üniversitesi Bilimsel Araştırmalar Komisyonu Başkanlığı tarafından 2017-09-08-014 kodlu proje kapsamındaki desteklenmiştir. Ayrıca yazar 1059B191800747 kodlu projeye 2219-Yurtdışı Doktora Sonrası Araştırma Burs Programı kapsamındaki desteklerinden dolayı Türkiye Bilimsel Araştırmalar Kurumu'na teşekkür eder.

\section{KAYNAKÇA}

[1] B. L. Mordike and T. Ebert, "Magnesium Properties - applications - potential," Mater. Sci. Eng. A, vol. 302, no. 1, pp. 37-45, 2001.

[2] I. Polmear, D. StJohn, J.-F. Nie, and M. Qian, "The Light Metals," in Light Alloys, 5th ed., Boston: Elsevier, 2017, pp. 1-29.

[3] K. S. Yoshiki-Gravelsins, J. M. Toguri, and R. T. C. Choo, "Metals production, energy, and the environment, part I: Energy consumption," JOM, vol. 45, no. 5, pp. 15-20, May 1993.

[4] C. 1. Mendis and A. Singh, "Magnesium Recycling: To the Grave and Beyond," JOM, vol. 65, no. 10, pp. 1283 1284, Oct. 2013.

[5] G. Yarkadaş, L. C. Kumruoğlu, and H. Şevik, "The effect of Cerium addition on microstructure and mechanical properties of high pressure die cast $\mathrm{Mg}-5 \mathrm{Sn}$ alloy," Mater. Charact., vol. 136, no. November 2017, pp. 152-156, Dec. 2018.

[6] G. Germen, G. Yarkadaş, and H. Şevik, "Influence of strontium addition on the wear behavior of $\mathrm{Mg}-3 \mathrm{Al}-3 \mathrm{Sn}$ alloys produced by gravity casting," Mater. Test., vol. 57, no. 11-12, pp. 997-1000, Nov. 2015.

[7] I. P. Moreno, T. K. Nandy, J. W. Jones, J. E. Allison, and T. M. Pollock, "Microstructural characterization of a die-cast magnesium-rare earth alloy," Scr. Mater., vol. 45, no. 12, pp. 1423-1429, 2001.

[8] S. Özarslan, H. Şevik, and İ. Sorar, "Microstructure, mechanical and corrosion properties of novel $\mathrm{Mg}-\mathrm{Sn}-\mathrm{Ce}$ alloys produced by high pressure die casting," Mater. Sci. Eng. C, vol. 105, p. 110064, Dec. 2019. 
[9] A. Gökçe, F. Fındık, and A. O. Kurt, "Alüminyum ve Alaşımlarının Toz Metalurjisi İşlemleri - Powder Metallurgy Processing of Aluminum Alloys," Engineer\&Machinery, vol. 58, no. 686, pp. 21-47, 2017.

[10] R. M. German, Sintering: from Empirical Observations to Scientific Principles, no. October. California: Elsevier, 2014.

[11] R. Tandon and D. Madan, "Emerging Applications Using Magnesium Alloy Powders: A Feasibility Study," in Magnesium Technology 2014, M. Alderman, M. V Manuel, N. Hort, and N. R. Neelameggham, Eds. Cham: Springer International Publishing, 2014, pp. 21-25.

[12] P. Burke, Y. G. Kipouros, W. D. Judge, and G. J. Kipouros, "Surprises and Pitfalls in the Development of Magnesium Powder Metallurgy Alloys," in Magnesium and Its Alloys, 1st ed., L. Dobrzanski, M. Bamberger, and G. Totten, Eds. Boca Raton, FL: CRC Press, 2019, pp. 337-373. [13] A. Gökçe, F. Findik, and A. O. Kurt, "Effects of Sintering Temperature and Time on the Properties of $\mathrm{Al}-\mathrm{Cu}$ PM Alloy," Pract. Metallogr., vol. 54, no. 8, pp. 533-551, 2017.

[14] A. Gökçe, F. Findik, and A. O. Kurt, "Sintering and aging behaviours of Al4CuXMg PM alloy," Can. Metall. Q., vol. 55, no. 4, pp. 391-401, 2016.

[15] R. M. German, A - Z of Powder Metallurgy. Michigan: Elsevier, 2005.

[16] S. K.R, M. S, M. S. K. Kara, and A. L, "Influence of Powder Composition \&amp; Morphology on Green Density for Powder Metallurgy Processes," Int. J. Innov. Res. Sci. Eng. Technol., vol. 04, no. 01, pp. 18629-18634, Jan. 2015.

[17] J. K. Thompson, W. Li, S. J. Park, A. Antonyraj, R. M. German, and F. Findik, "Utilisation of silicon rubber to characterise tool surface quality during die compaction," Powder Metall., vol. 52, no. 3, pp. 238-243, Sep. 2009.

[18] R. M. German, Particulate Composites. Cham: Springer International Publishing, 2016.

[19] P. Burke and G. J. Kipouros, "Development of magnesium powder metallurgy AZ31 alloy using commercially available powders," High Temp. Mater. Process., vol. 30, no. 1-2, pp. 51-61, 2011.

[20] D. W. Heard, I. W. Donaldson, and D. P. Bishop, "Metallurgical assessment of a hypereutectic aluminumsilicon P/M alloy," J. Mater. Process. Technol., vol. 209, no. 18-19, pp. 5902-5911, 2009.

[21] A. Ibrahim, D. P. Bishop, and G. J. Kipouros,
"Sinterability and characterization of commercial aluminum powder metallurgy alloy Alumix 321," Powder Technol., vol. 279, pp. 106-112, 2015.

[22] G. S. Upadhyaya, "Sintered metallic and ceramic materials - preparation, properties and applications," Mater. Des., vol. 22, no. 4, Jun. 2001.

[23] A. Gökçe, F. Findik, and A. O. Kurt, "Effects of Mg content on aging behavior of A14CuXMg PM alloy," Mater. Des., vol. 46, pp. 524-531, 2013.

[24] G. E. Dieter and D. J. Bacon, Mechanical metallurgy, vol. 3. McGraw-Hill New York, 1986.

[25] R. M. German, Liquid Phase Sintering. Boston, MA: Springer US, 1985.

[26] R. M. German, P. Suri, and S. J. Park, "Review: Liquid phase sintering," J. Mater. Sci., vol. 44, no. 1, pp. 1 39, 2009.

[27] R. M. German and J. W. Dunlap, "Processing of iron-titanium powder mixtures by transient liquid phase sintering," Metall. Trans. A, vol. 17, no. 2, pp. 205-213, Feb. 1986.

[28] M. Wolff, C. Blawert, M. Dahms, and T. Ebel, "Properties of Sintered Mg Alloys for Biomedical Applications," Mater. Sci. Forum, vol. 690, pp. 491-494, 2011.

[29] H. . Yao, Y. Li, and A. T. . Wee, "An XPS investigation of the oxidation/corrosion of melt-spun Mg," Appl. Surf. Sci., vol. 158, no. 1-2, pp. 112-119, May 2000.

[30] Z. Y. Liu, T. B. Sercombe, and G. B. Schaffer, "The effect of particle shape on the sintering of aluminum," Metall. Mater. Trans. A Phys. Metall. Mater. Sci., vol. 38, no. 6, pp. 1351-1357, 2007.

[31] P. Burke, G. J. Kipouros, D. Fancelli, and V. Laverdiere, "Sintering Fundamentals of Magnesium Powders," Can. Metall. Q., vol. 48, no. 2, pp. 123-132, 2014. [32] M. S. Syaza Nabilla, C. D. Zuraidawani, and M. N. Derman, "Fab8+ 